\title{
Para que desta vez seja diferente
}

\section{FRANCISCO EDUARDO PIRES DE SOUZA I}

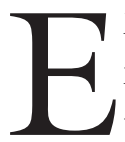

M POUCOS meses a situação da economia brasileira sofreu uma brusca inflexão. Já havíamos avançado bastante no segundo semestre de 2016 e parecia que a economia mergulhava ainda mais fundo na maior crise econômica da história republicana, sem perspectivas de encontrar uma luz no fim do túnel. No início de 2017, contudo, o horizonte econômico se abriu e a economia agora ingressa de forma clara num processo de recuperação.

Salvo por novos eventos de excepcional dramaticidade no plano político, a economia seguirá seu curso de expansão que, provavelmente, será mais forte em curto e médio prazos do que atualmente se imagina. A continuidade da recuperação é agora fundamentalmente uma questão política, não econômica.

O debate sobre o que fazer para a economia se recuperar virou, a meu ver, um tema superado. O crucial, a essa altura, é voltar os olhos para o futuro, com o foco nas políticas econômicas e na construção de um modelo de crescimento consistente, evitando os erros críticos do passado recente. Estamos numa encruzilhada e a escolha de um caminho deve definir se vamos finalmente entrar numa rota de crescimento de longo prazo, que nos leve a uma aproximação progressiva do grupo de economias avançadas, ou se vamos ser condenados à mediocridade dos voos de galinha.

O presente texto está dividido em três partes, fora esta introdução. $\mathrm{Na}$ primeira delas faz-se uma interpretação das origens da crise atual que, embora identifique a existência de múltiplas causas, considera que existe um determinante central relacionado à inconsistência do modelo econômico adotado desde meados da década passada. Esse diagnóstico é importante para pensar o que fazer para garantir que se transforme a recuperação que recém se inicia num processo de desenvolvimento de longo prazo. Na segunda parte, faz-se uma brevíssima análise do processo de recuperação atual. Ao compará-lo com o ocorrido a partir do segundo semestre de 2003 , conclui-se que desta vez corre-se o risco de não ter sequer um ciclo expansivo relativamente longo (como o ocorrido de 2004 a 2011). Caso não acertemos num modelo de crescimento adequado, muito provavelmente teremos apenas um voo de galinha. A terceira parte conclui com uma discussão sintética sobre a natureza das políticas requeridas para garantir que ingressemos num verdadeiro ciclo de desenvolvimento sustentado.

\section{Como chegamos a esta crise?}

A recessão dos últimos três anos já pode ser considerada como a mais 
profunda crise em mais de cem anos (Tabela 1). Com ela foi-se o sonho do crescimento robusto, sustentado e socialmente justo, que o país alimentou durante alguns anos - do meio da década passada ao início da atual. De fato, quando consideramos o ciclo completo, do início da expansão, em 2004, ao fundo da crise em 2016, o crescimento anual médio foi de 2,5\%, nada muito distante da quase estagnação em que o país se encontrava desde o início da década de 1990.

Tabela 1 - As quatro maiores recesões dos últimos 100 anos

\begin{tabular}{c|c|c}
\hline Ano inicial & Duração (anos cheios) & Queda acumulada do PIB (\%) \\
\hline 1930 & 2 & $-5,3$ \\
\hline 1981 & 3 & $-6,3$ \\
\hline 1990 & 3 & $-3,9$ \\
\hline $2015^{(1)}$ & 2 & $-7,2$ \\
\hline
\end{tabular}

Fonte: Ipedata, IBGE, PIB Trimestral e Estatísticas do Século XX.

(1) Em termos trimestrais, com ajuste sazonal, a recessão iniciou-se no $2^{\circ}$ trimestre de 2014 , teve uma duração de 11 trimestres, com queda acumulada do PIB de 9\%.

Entender o que deu errado é fundamental não tanto para a retomada de curto e médio prazos, mas sim para evitar mais uma história de fracasso na busca da consolidação de um processo desenvolvimento de longo prazo da economia brasileira.

$\mathrm{Na}$ história do capitalismo, as recessões mais longas e profundas são aquelas associadas a crises financeiras (Lo; Rogoff, 2015). No presente caso brasileiro, contudo, seguramente não é esse o caso. Outra peculiaridade do atual evento crítico na economia é que, ao contrário de outros episódios recessivos do passado brasileiro, desta vez não se pode identificar uma restrição externa entre suas causas. Descartadas essas duas explicações clássicas, resta concluir que uma crise dessa magnitude deve ser o produto de múltiplas causas, entre elas a crise política, fenômenos cíclicos endógenos, determinantes externos, a política econômica e o modelo de crescimento. Mesmo aceitando que todos eles tenham tido seu papel, para avançar na compreensão do fenômeno é fundamental hierarquizar os determinantes, identificando o que é principal e o que são agravantes.

Há uma tendência no debate brasileiro, sobretudo na imprensa, para a explicação mais fácil de todas: os erros de política econômica da gestão Dilma (já que sob Lula a economia cresceu com vigor). À esquerda, a crítica se centra no (suposto) conservadorismo da política econômica a partir de 2011 (ex.: Serrano; Summa, 2015). Do centro e da direita vem a crítica sobre o excesso de intervencionismo, o expansionismo monetário (com destaque para o episódio da redução dos juros no segundo semestre de 2011) e fiscal. Parece inegável que houve graves erros de política econômica, sobretudo a partir de 2012, mas o diagnóstico de que a crise se deve fundamentalmente a eles, no sentido de que, mantidas as políticas anteriores, teríamos evitado a crise, parece ser um diagnós- 
tico prejudicado por motivações políticas e ideológicas. Uma das alternativas a esse tipo de diagnóstico é a que se propõe a seguir. $\mathrm{O}$ argumento parte da identificação de falhas fundamentais (de consistência) no modelo de crescimento em curso, que estavam levando a desequilíbrios graves mesmo sob as excepcionais condições externas que cercaram a maior parte do governo Lula. Vejamos por quê.

Considere-se inicialmente o balanço de pagamentos. Partindo de um superávit em conta corrente de 1,7\% do PIB em 2004, chegou-se em 2014 a um déficit em transações correntes de 4,2\% do PIB: um aumento de 5,9 pontos percentuais do PIB. Mas em 2010 (último ano da gestão Lula) esse déficit já havia alcançado a marca de $3,4 \%$ do PIB. Essa deterioração ocorreu apesar do benefício resultante dos termos de troca. Não fosse isso, vale dizer, considerando-se os termos de troca constantes, a piora das transações correntes, em relação a 2004, teria sido de $5,3 \%$ do PIB até 2010 , e $7,7 \%$ do PIB até 2014 . Além disso, é evidente que, não fosse a forte desaceleração do PIB, que tem um efeito contracionista sobre as importações, este último resultado teria sido ainda pior. Essa progressão do déficit em conta corrente é um sintoma de que havia um desequilíbrio subjacente levando a um processo insustentável das contas externas que mais cedo ou mais tarde provocaria uma crise. Não chegou a esse ponto: a dramática queda do nível de atividades em 2015 e 2016 corrigiu uma parte importante do déficit.

Considere-se agora a inflação. Entre janeiro de 2004 e dezembro de 2010 a taxa de inflação, medida pelo IPCA, ficou numa média de 5,3\%, e em três dos sete anos ela ficou no centro da meta ou abaixo dele. Sem dúvida parece um bom resultado quando comparado ao observado no período Dilma (20112015) quando a média da inflação ficou em $7,1 \%$ e em nenhum ano foi alcançado o centro da meta, de $4,5 \%$. A princípio essa comparação referendaria a tese de que o problema foi a piora na qualidade da política econômica.

Note-se, contudo, que o resultado do período 2004-2010 foi garantido por uma inflação de comercializáveis de apenas $4,5 \%$ em média naquele período. E que essa foi viabilizada por um processo de apreciação cambial sistemático, interrompido apenas brevemente após a crise internacional, para depois retomar seu curso anterior e prosseguir até meados de 2011. De 2004 a 2010, ao longo do mesmo período de bons resultados inflacionários acima referidos, a taxa de câmbio nominal teve uma queda de $40 \%$ (e $45 \%$ em termos reais efetivos).

O cobertor curto então fica evidente. Primeiro a inflação foi reprimida pelo extraordinário barateamento do preço do dólar, que, como não podia deixar de ser, acabaria se revelando insustentável. Depois, com a depreciação cambial que começa a ocorrer a partir do segundo semestre de 2011, a taxa de inflação começa a subir e o governo "puxa o cobertor", criando tensões em outras áreas da economia: repressão tarifária (comprometendo empresas do setor de 
energia), desonerações de impostos e subsídios (afetando negativamente as contas públicas), e assim por diante. Havia obviamente um desequilíbrio subjacente, que era reprimido, primeiro, pelo câmbio apreciado, depois por tarifas contidas e desequilíbrio fiscal - todas elas manifestações de algo insustentável.

E como a repressão da inflação é sempre imperfeita, a inflação de fato acabou entrando em processo de elevação a despeito dos expedientes adotados. Em 2015, com a desrepressão tarifária, ela escalou para 10,7\%. O pior de tudo é que, dado o histórico brasileiro, marcado por uma cultura inflacionária não totalmente extinta, a indexação formal e a informal voltam a partir de níveis não muito altos de inflação, fenômeno do qual muitas evidências vinham se acumulando nos anos recentes. A resistência que se cria então à queda da inflação fica patente no altíssimo custo econômico e social para reduzi-la. De fato, só nos últimos meses de 2016, depois de quase dois anos de forte queda nos níveis de produção, e alta dramática do desemprego, é que a inflação (em especial a de serviços) começou a ceder.

Em suma, no que se refere tanto ao balanço de pagamentos quanto à inflação, somente mediante um sacrifício econômico e social sem comparação internacional foi possível conter (ou reprimir) os desequilíbrios. Ou seja, a crise já estava plantada há pelo menos uma década, embora eventos exógenos pudessem antecipá-la ou postergá-la.

Considere-se, em terceiro lugar, a evolução das contas públicas. Entre dezembro de 2013 e dezembro de 2016 , a dívida do governo geral subiu quase 20 pontos percenturais do PIB, de $51,5 \%$ para $69,5 \%$ do PIB. E de acordo com as projeções do Instituto Fiscal Independente, do Senado Federal, deverá alcançar $84,3 \%$ do PIB em 2021, mesmo com a PEC do teto dos gastos aprovada (IFI, 2017).

Muitos interpretam o agravamento fiscal dos últimos anos como resultado da política expansionista do governo Dilma (principalmente a de 2014); outros, como subproduto exclusivo da recessão. No entanto, embora toda recessão provoque um aumento do déficit fiscal, existe, também no plano fiscal, um desequilíbrio subjacente cuja manifestação, nos números do déficit primário e da dívida pública, foi tão somente antecipada e agravada pela recessão, ou pela política eleitoral de 2014. Essa tendência vem, a rigor, desde finais da década de 1990. De 1999 a 2015 as despesas primárias do governo central subiram, em média, $6 \%$ acima da inflação medida pelo IPCA, portanto muito acima do crescimento do PIB real. Isso só foi conciliável com superávits primários (até 2013) porque a carga tributária subia em linha com o aumento dos gastos.

É evidente que, mais cedo ou mais tarde, a arrecadação tributária esbarraria num limite, o que, no caso do governo central, começou a ocorrer no final da década passada. A recessão dos últimos dois anos, portanto, apenas aprofundou um movimento que já começava a ocorrer. Porém as despesas, ao contrário da carga tributária, apresentavam elevado grau de rigidez (dadas as regras orça- 
mentárias vigentes, como vinculações e indexações) que tendem a manter um ritmo de crescimento real elevado, quando não (como no caso da Previdência) agravá-lo. Não à toa, algum grau de convergência passou a ser observado entre o diagnóstico da equipe econômica do governo Dilma, nos seus últimos meses, e a dos seus críticos. ${ }^{1}$

O que importa destacar aqui é que a política fiscal, a despeito de seus méritos sociais, estava assentada num modelo, que vinha desde a década de 1990, que a tornaria economicamente insustentável quando não fosse mais possível elevar a carga tributária. O amadurecimento da questão, a partir do debate e da investigação empírica ocorridos nos últimos anos, indica que o problema foi muito além da questão (política) de definir um nível de gasto social que represente a escolha da sociedade (e que sendo assim deveria corresponder á aceitação social de um nível de tributação compatível com a escolha). O problema com o comportamento dos gastos públicos não era de nível e sim de trajetória de crescimento - muito acima do ritmo possível de expansão da economia e, portanto, insustentável.

Recapitulando o argumento desenvolvido até aqui: os crescentes déficits fiscal e de transações correntes, lado a lado com uma inflação crescente são sintomas claros de que havia graves inconsistências no modelo e nas políticas econômicas em curso. Além disso, procurou-se mostrar que nenhum desses desequilíbrios surgiu com a mudança da política econômica operada a partir de 2011, embora, no caso fiscal e inflacionário, tenham sido por ela agravados.

$\mathrm{Na}$ origem do problema está a resposta do governo a um dilema de política econômica que emergiu na segunda metade da década passada. O conjunto de iniciativas nos campos creditício, salarial e fiscal criou um ambiente fortemente expansionista a partir de 2004. Os ventos propícios que sopravam do exterior também contribuíram para afetar positivamente as expectativas e inflar a demanda. O ritmo de expansão da demanda se mostrou claramente excessivo, superando por ampla margem o crescimento da produção, como mostra o Gráfico 1. Como reconciliar a demanda em acelerada expansão com a produção possível?

A solução natural de mercado, numa economia fechada, seria a inflação. Essa corroeria o valor real dos salários e dos gastos públicos, rebaixando a demanda agregada em direção a níveis compatíveis com a oferta. Numa economia aberta, o aumento da importação líquida de bens e serviços poderia contribuir (embora não indefinidamente) para fechar o hiato entre demanda e oferta, abrindo assim uma segunda via para equacionar o problema. Haveria ainda um terceiro caminho: a adoção de políticas de contenção do crédito e do gasto público para moderar a expansão da demanda agregada adaptando-a ao ritmo possível de crescimento da produção, lado a lado com políticas de proteção cambial. 


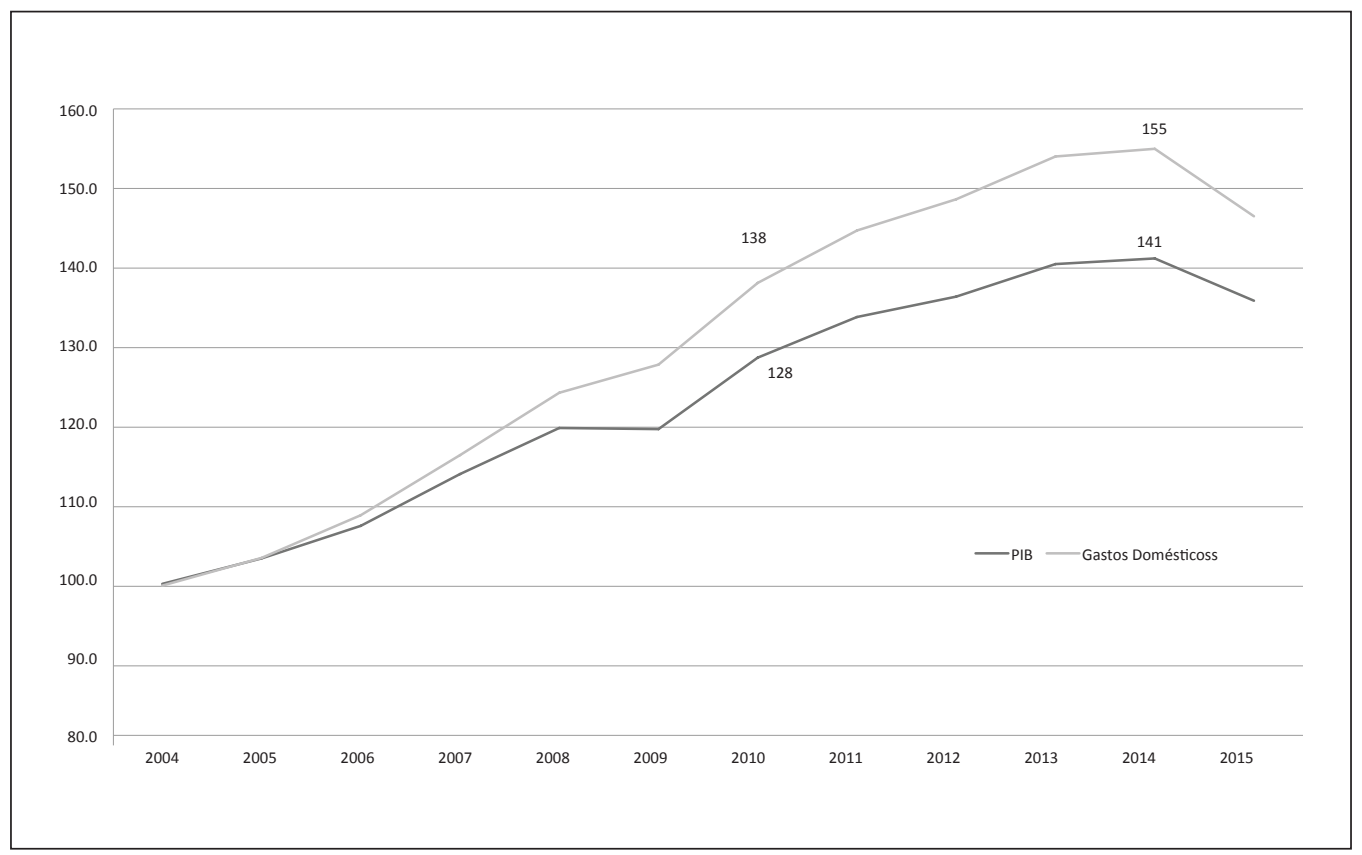

Fonte: IBGE, Contas Nacionais Trimestrais, $3^{\circ}$ trimestre de 2016.

(1) Consumo das famílias e do Governo + FBCF.

Gráfico 1 - Evolução do PIB e dos gastos domésticos ${ }^{1}$ a preços constantes $(2004=$ 100).

É claro que, em qualquer caso, políticas de expansão da oferta, como a criação de um ambiente favorável ao investimento, investimentos públicos em infraestrutura e em educação etc., contribuiriam para fechar a equação. Mas é sabido que tais políticas, mesmo se bem formuladas e executadas, produzem resultados num prazo frequentemente incompatível com a dinâmica dos desequilíbrios macroeconômicos.

Como o governo reagiu diante das alternativas anteriores? $\mathrm{O}$ caminho da moderação das políticas fiscais e creditícias expansionistas foi rejeitado, o que jogou nos ombros do Banco Central a responsabilidade por fechar o hiato, já que o governo tampouco aceitou os custos sociais e políticos da aceleração da inflação. Daí resultou um modelo de política econômica em que se pisava no freio com a política de juros e no acelerador com todas as demais. Como essas últimas prevaleceram em termos de expansão da demanda (o que bloqueava o efeito dos juros via contenção da demanda), a política monetária passou a operar fundamentalmente através do canal do câmbio. Em outras palavras, o câmbio deveria apreciar tanto quanto fosse necessário para conter os preços dos comercializáveis de forma a compensar a trajetória dos demais preços e colocar a inflação na meta.

Essa escolha definiu os contornos do padrão de crescimento. Em termos da estrutura do crescimento, ele se caracterizou pela liderança dos setores não 
comercializáveis da economia coadjuvado pelos setores comercializáveis intensivos em recursos naturais, ao mesmo tempo que ocorria um claro processo de desindustrialização. Em termos macroeconômicos por uma forte expansão dos gastos públicos e privados, queda da taxa de poupança doméstica, e progressivo aumento do déficit em transações correntes.

A escolha desse modelo de crescimento correspondeu a uma decisão de avançar pela linha de menor resistência. Qualquer outra alternativa implicaria maiores sacrifícios (ou, talvez fosse mais apropriado dizer, menores bônus) em curto prazo. Mas talvez não tenha sido fruto apenas da pressão do interesse político mais imediato, ou da ilusão de que a melhoria dos termos de troca iria prosseguir para sempre e salvar o modelo. Uma lógica de equilíbrio intertemporal poderia justificá-la: os desequilíbrios presentes poderiam ser financiados durante um período, ao longo do qual os empresários aumentariam seus investimentos motivados pelo aumento sustentado da demanda agregada. Dado um prazo suficiente, o aumento da capacidade produtiva permitiria atender a demanda, eliminando-se o hiato que, alternativamente, provocaria o déficit em conta corrente e/ou pressionaria a inflação. Eventualmente, seria possível gerar superávits para pagar as dívidas acumuladas nos períodos de déficits.

Com o benefício da visão retrospectiva, sabemos que a lógica do equilíbrio intertemporal não funcionou. O que deu errado? Vejamos por partes. Primeiramente, no que se refere à indústria de transformação, um dos carros-chefes do investimento no país, a combinação de câmbio apreciado, salários reais subindo acima da produtividade e taxas de juros muito elevadas - todos eles aspectos indissociáveis do modelo escolhido - golpearam a rentabilidade e consequentemente a capacidade da indústria manufatureira de competir, o que levou a perdas de fatias do mercado interno e externo (Gráfico 2). Isso evidentemente afetou negativamente o investimento, a despeito do efeito positivo do câmbio apreciado sobre a aquisição de bens de capital importados. É sintomático desse quadro que não apenas a taxa de investimento agregada cresceu muito menos do que se considerava necessário para sustentar uma taxa de crescimento do PIB da ordem de 4,5\% do PIB, como também o aumento do investimento foi bastante viesado para produtos típicos da Formação Bruta de Capital Fixo (FBCF) de setores não comercializáveis. Os investimentos em equipamentos de transporte, por exemplo, que representavam cerca de 7\% do total da FBCF no início da década passada, somaram quase um terço do aumento do investimento ao longo da década. Somente o investimento em automóveis representou $16 \%$ do aumento da FBCF na década passada. ${ }^{2}$

Se a indústria investiu pouco e estagnou a partir do final de 2007, o setor de serviços, que não sofreu os efeitos da competição externa (e portanto da apreciação cambial), cresceu com baixa produtividade e elevado ritmo de absorção de mão de obra (Arbache, 2016). À medida que, sob o peso da reduzida produtividade e do progressivo esgotamento do excedente de mão de obra, esse 
setor perdeu fôlego, sua resposta aos aumentos de demanda nominal passou a se dar, cada vez mais, pelo aumento de preços em detrimento do incremento da produção.

A conclusão é que a crise atual não foi simplesmente o resultado da mudança na política econômica operada no governo Dilma, embora tenha sido por ela agravada. Não foi apenas fruto da crise política, embora essa tenha se entrelaçado num mecanismo de feedback com a crise econômica. Também não pode ser pensada como uma crise cíclica, ainda que mecanismos que tipicamente produzem desacelerações do ciclo econômico estivessem em operação. A despeito de suas múltiplas causas, algumas ad hoc, houve um determinante fundamental. O argumento aqui desenvolvido é que a crise é um produto inevitável dos desequilíbrios associados a um modelo econômico forjado por opções de política econômica adotadas desde meados da década passada, com as características acima descritas.

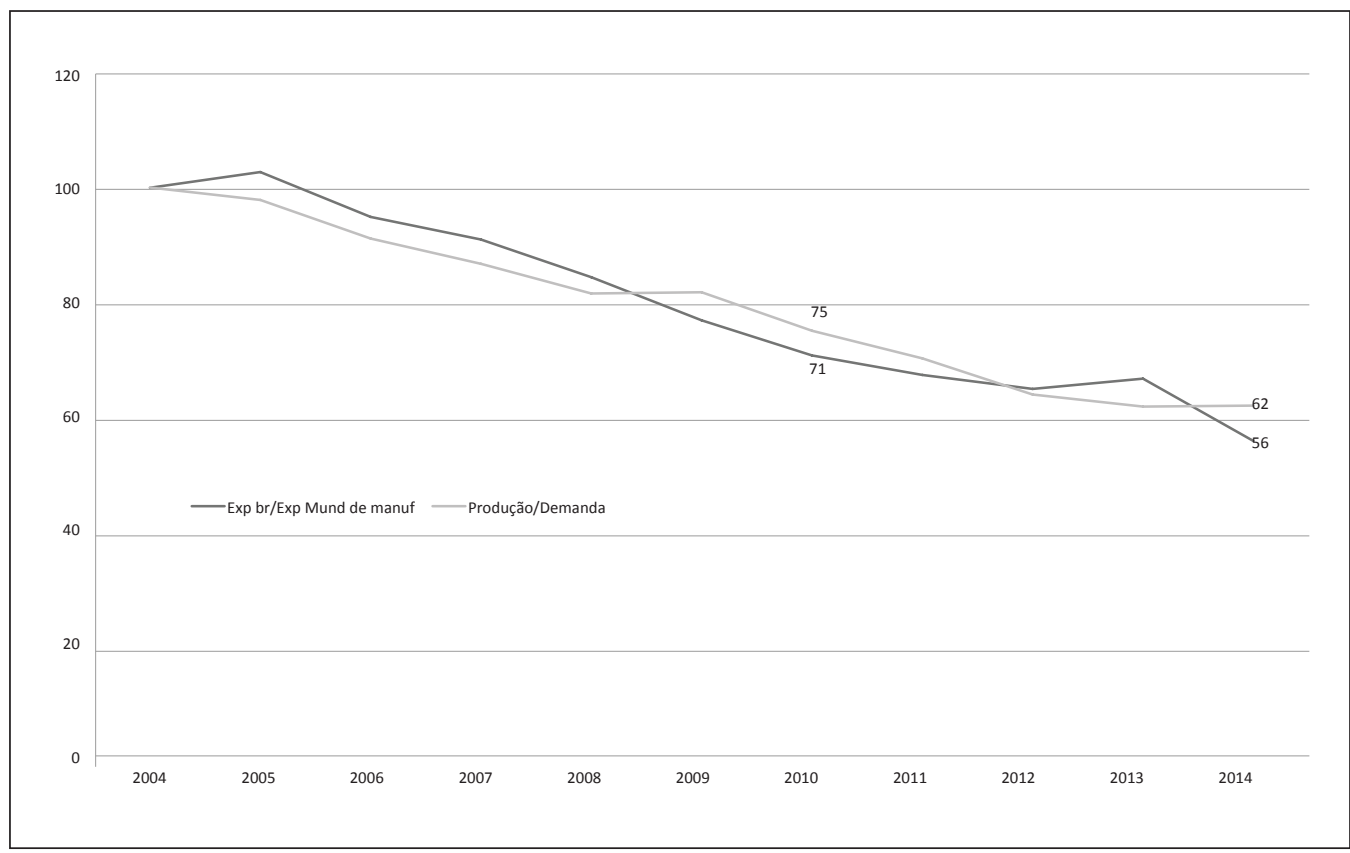

Fonte: OMC, Funcex e IBGE.

Gráfico 2 - Evolução da participação da indúsutria de transformação brasileira nos mercados externo e interno de manufaturados, em volume $(2004=100)$.

\section{Como saímos do fundo do poço}

A recuperação que começou a se desenhar entre o final de 2016 e início de 2017 tem componentes endógenos (cíclicos) e exógenos (políticos, internacionais e alguns acidentais), que juntos estão criando uma massa crítica de incentivos capazes de dar partida a uma recuperação. 
Quanto aos ingredientes cíclicos, é natural que surjam após uma longa recessão, ao longo da qual gastos (e o crédito) foram severamente reprimidos. Basta lembrar aqui o caso da indústria de bens de consumo duráveis, cuja produção baixou $34 \%$ nos últimos quatro anos (segundo a PIM-IBGE), na esteira de uma forte queda do consumo. Emblemático, dentro dessa categoria de uso, é o caso da indústria automobilística. Depois de atingir um pico de 3,5 milhões de autoveículos licenciados nos 12 meses encerrados em outubro de 2013, as vendas no mercado interno despencaram por três anos, com o número de licenciamentos baixando para cerca de 2 milhões de veículos nos 12 meses encerrados em outubro de 2016 - nível semelhante ao de 12 anos antes. É claro que nesse período a frota envelheceu e a necessidade de reposição cresceu. Em tais condições de demanda reprimida, basta alguma redução da incerteza sobre o futuro da economia e da política, e algum alívio nas condições de crédito (ambas as condições preenchidas no período recente), para que a demanda volte a crescer. Na medida (amortecida) de 12 meses, isso começou a ocorrer em outubro de 2016. A produção também voltou a crescer nesse período, porém reforçada pelo aumento das exportações - fato que influenciou o comportamento dos manufaturados em geral.

Além dos aspectos cíclicos da economia propriamente dita, há também o ciclo da política monetária. Depois de um longo período de altas taxas de juros e de forte recessão, a inflação finalmente começou a ceder e uma fase de redução da Selic começou e vem se acelerando, provocando quedas importantes nos juros futuros - fator que sempre foi seguido de recuperação da economia.

Reforçando os fatores cíclicos, a recuperação da governabilidade política (pelo menos no que diz respeito à capacidade de aprovação de medidas relevantes na área econômica), juntamente com uma relativa melhoria das condições econômicas internacionais (refletidas nos preços de algumas commodities) tiveram efeitos positivos sobre os índices de confiança de produtores e consumidores, o que contribui para a retomada das atividades.

Entre os fatores acidentais, pode-se destacar a excelente safra agrícola, que além de conter os preços dos alimentos, ajudando o processo de queda da inflação e dos juros, aumenta a renda dos produtores, o que incentiva o consumo de duráveis, máquinas agrícolas etc.

Por fim, na esteira de uma longa recessão, como resultado de um ajuste doloroso, os preços relativos básicos da economia (salários, juros, câmbio) ${ }^{3}$ estão mais próximos de uma configuração compatível com o incentivo ao investimento, inclusive nos setores comercializáveis.

Em suma, um conjunto relativamente poderoso de circunstâncias milita para uma retomada da economia. Em face dessa espécie de "alinhamento dos astros", a menos de um novo descarrilamento político - algo que obviamente não está fora do campo das possibilidades - a economia deve prosseguir em sua rota de recuperação. Se for assim, cabe perguntar sobre o alcance dessa recuperação. 
A última vez em que o país se viu diante de um conjunto de circunstâncias semelhantes às atuais, que posicionam a economia no ponto de decolagem de um ciclo de crescimento, foi no segundo semestre de 2003. Naquela época, porém, as condições eram bem mais favoráveis para um ciclo mais prolongado. Muito resumidamente, o grau de endividamento das famílias era baixíssimo (menos de $20 \%$ da renda, versus $42 \%$ ao final de 2016 ); as transações correntes haviam entrado no terreno positivo (superávit de $0,7 \%$ do PIB, contra déficit de 1,3\% em 2016); a situação fiscal era mais confortável (superávit primário de 3,2\% do PIB em dezembro de 2003 versus déficit de 2,5\% em finais de 2016); e por fim, uma situação internacional muito mais favorável, em meio a um ciclo de expansão vigoroso, capitaneado pela China. No presente, a folga existente para um crescimento extensivo (sem grande aumento de produtividade) e puxado pela demanda, alimentada por um boom de crédito e pelo gasto público, é muito mais estreita. Se não formos capazes de evitar os erros cometidos na década passada, muito provavelmente teremos, desta vez, um voo de galinha.

\section{A volta do voo da galinha?}

Talvez o voo da galinha seja o caminho "default", pois parece evidente que existem forças econômicas poderosas que tendem a empurrar a economia brasileira no caminho de um modelo caracterizado, no plano da estrutura produtiva, pela liderança dos setores de serviços e agromineral e, no plano macroeconômico, pela baixa poupança doméstica, elevado déficit em conta corrente e câmbio apreciado. É a linha de menor resistência. Para ir para outra trajetória é necessário, além de se ter um plano consistente, ter suporte político.

Colocada a questão num alto nível de generalidade, o caminho para a superação da síndrome da quase estagnação requer que se esquive dos extremos do voluntarismo inconsequente e do ultraliberalismo. Isso significa, de um lado, aceitar que não basta fazer políticas de expansão da demanda, na crença de que a oferta sempre irá acompanhá-la, não importando o alinhamento dos preços básicos da economia, os déficits e as dívidas, bem como os limites de capacidade produtiva. E de outro, não abdicar da capacidade do governo de influir nos mercados, através de suas políticas macroeconômicas, não apenas para garantir a melhor distribuição da renda possível - respeitados os limites do incentivo ao investimento e ao crescimento -, mas também para evitar que influxos excessivos de capital externo, ou os excessos de arrecadação pública e de divisas resultantes de um eventual boom de demanda por commodities causem danos de médio e longo prazos às finanças públicas e ao dinamismo dos setores comercializáveis da economia.

Traduzindo os requisitos acima para o plano mais concreto das políticas econômicas, o primeiro passo, que em grande medida já está sendo dado, é a realização de reformas com o objetivo de colocar os gastos e a dívida pública numa trajetória sustentável de longo prazo. Ainda no plano das reformas fiscais, ampliar a flexibilidade orçamentária, de maneira que essa política possa ser usada 
de forma mais efetiva em momentos de desequilíbrio macroeconômico, retirando assim parte do peso do controle da inflação de cima da política monetária.

Em relação à política monetária, é hora de se pensar se não devemos rumar para um regime que contemple mais de um objetivo e mais de um instrumento. Ainda que a atual discussão sobre política monetária, provocada pelos artigos de Lara Resende (2017a; 2017b), seja extremamente instigante, há um outro debate internacional (ver, por exemplo, Blanchard et al., 2014; Ostry et al., 2012) igualmente (ou mais) relevante para a presente situação brasileira. Em particular a ideia de incorporar a taxa de câmbio aos objetivos da política econômica (inclusive a monetária) deveria ser considerada. Há muitas formas de se influenciar a taxa de câmbio (sem praticar políticas insustentáveis) de que se pode lançar mão, com o objetivo de impedir que esse preço essencial fique sujeito ao acaso de forças exógenas (crises políticas, flutuações dos preços de commodities, e alterações nas políticas monetárias dos principais bancos centrais etc.), algumas delas acidentais e efêmeras.

Por fim, existe um amplo campo de políticas relacionadas ao lado da oferta, indo do investimento à produtividade, em relação às quais há um grande acervo de experiência obtido com as iniciativas dos últimos anos, com seus erros e acertos, sobretudo no que se refere às políticas de investimento em infraestrutura. Não foi objeto do presente texto tratar desse tipo de política. Está suposto no texto apenas que, se bem resolvidas, elas podem acelerar o ritmo do crescimento futuro, mas sem a criação de um contexto macroeconômico apropriado, conforme discutido acima, elas seriam inócuas.

\section{Notas}

1 A Secretaria de Política Econômica do Ministério da Fazenda, quando este ainda se encontrava sob o comando do ministro Nelson Barbosa, produziu um documento (SPE, 2016) em que faz um diagnóstico da rigidez dos gastos orçamentários como fator determinante de uma expansão insustentável dos gastos correntes, no qual se conclui pela necessidade de reformas, destacando-se duas: "uma reforma da Previdência, cuja referência principal deve ser estabilizar no médio prazo a despesa em \% do PIB. A segunda iniciativa passa por uma reforma mais ampla do gasto obrigatório que estabeleça um limite para a sua expansão". Para um diagnóstico produzido por críticos do governo de então, ver Almeida Jr., Lisboa e Pessoa (2015).

2 Cálculos do autor com base na Matriz de Absorção do Investimento, produzida pelo Instituto de Economia da UFRJ. As planilhas com os dados disponíveis, de 2000 até 2009, foram gentilmente cedidas por Thiago de Holanda Lima Miguez, a quem agradeço.

3 Bresser-Pereira tem insistido, com razão, no argumento da necessidade de se colocar os preços macroeconômicos no lugar certo como condição (que faltou no ciclo anterior) para um crescimento sólido da economia brasileira. Ver Bresser-Pereira (2015), que acrescenta aos preços citados a taxa de lucro e a taxa de inflação. 
Referências

ALMEIDA JUNIOR, M.; LISBOA, M. B.; PESSOA, S. O ajuste inevitável- ou o país que se tornou velho antes de se tornar desenvolvido. Julho de 2015. Disponível em: <https://mansueto.files.wordpress.com/2015/07/o-ajuste-inevitc3alvel-vf_2.pdf>.

ARBACHE, J. Manufacturing, services and the productivity gap. Trabalho a ser publicado no Oxford Handbook of the Brazilian Economy. Versão de 12.12.2016.

BLANCHARD, O.; DELL'ARICCIA, G.; MAURO, P. Introduction: Rethinking Macro Policy II - Getting Granular. In: AKERLOF, G.; et al. What Have we Learned Macroeconomic Policy after the Crisis. s. 1.: IMF; MIT Press, 2014.

BRESSER-PEREIRA, L. C. A quase estagnação brasileira e sua explicação novo-desenvolvimentista. In: BARBOSA, N. et al. (Org.) Indústria e desenvolvimento produtivo no Brasil. s. 1.: Elsevier, 2015.

IFI. Relatório de Acompanhamento Fiscal. Senado Federal, Instituição Fiscal Independente (IFI), Brasília, 2017. Disponível em: <https://www12.senado.leg.br/ifi/public>.

LO, S.; ROGOFF, K. Secular stagnation, debt overhang and other rationales for sluggish growth, six years on. BIS Working Papers, n.482, jan. 2015.

OSTRY, J. D.; GHOSH, A. R.; CHAMON, M. Two Targets, Two Instruments: Monetary and Exchange Rate Policies in Emerging Market Economies. IMF Discussion Note, SDN/12/01, February 29, 2012.

RESENDE, A. L. Juros e conservadorismo intelectual. Valor Econômico, 13.1.2017a.

Teoria, prática e bom senso. Valor Econômico, 27.1.2017b.

SERRANO, F.; SUMMA, R. Demanda agregada e a desaceleração do crescimento econômico brasileiro de 2011 a 2014. Center for Economic and Policy Research, Washington, DC, agosto de 2015. Disponível em: <http://cepr.net/documents/publications/Brazil-2015-08- PORTUGUESE.pdf>.

SPE. Relatório de Análise Econômica dos Gastos Públicos Federais. Ministério da Fazenda, Secretaria de Política Econômica (SPE), maio de 2016. Disponível em: <http:// www.spe.fazenda.gov.br/notas-e-relatorios/relatorio_gasto_publico_federal_site.pdf>.

RESUMO - O presente texto parte da suposto de que a economia já se encontra em recuperação. Por isso o debate deveria se deslocar para o desenho do modelo de crescimento futuro. Este deveria garantir um processo de desenvolvimento sustentado que superasse a maldição da quase estagnação. As proposições nesse sentido são baseadas no diagnóstico de que o determinante central da atual crise é a inconsistência do modelo econômico adotado desde meados da década passada. Esse modelo, que levou a um processo de desindustrialização, estaria fundado, de uma óptica estrutural, na expansão dos setores produtores de commodities. Pelo lado macroeconômico, suas bases estariam assentadas em políticas de forte expansão da demanda, câmbio apreciado, levando a um déficit crescente em transações correntes, como mecanismo de reconciliação dos desequilíbrios.

PALAVRAS-CHAVE: Crescimento econômico brasileiro, Ciclo econômico e crise no Brasil, Desindustrialização e crise, Política econômica e crescimento. 
ABSTRACT - This paper takes for granted that the Brazilian economy is already recovering. Therefore, economic policy debate should focus on which requirements the economic model should meet to ensure that a bold process of development will follow the recovery, avoiding the curse of quasi-stagnation of the last decades. Some general proposals are made at the end of the paper, based upon the hypothesis that the main cause of the deep recession of the last three years was the inconsistency of the economic model put in place since the mid-2000. This model, based on the commodity-producing sectors, led to the deindustrialization of the Brazilian economy. On the macroeconomic side, the model was based on policies to boost domestic demand, leading to intense currency appreciation and an increasingly large current account deficit to reconcile aggregate demand and supply.

KEYWORDS: Brazilian economic growth, Economic cycle and crisis in Brazil, Deindustrialization and crisis, Economic policy and growth in Brazil.

Francisco Eduardo Pires de Souza é professor do Instituto de Economia da Universidade Federal do Rio de Janeiro (UFRJ). @ - fepsouza@ie.ufrj.br

Recebido em 5.3.2017 e aceito em 15.3.2017.

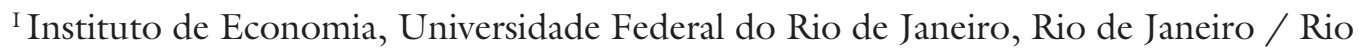
de Janeiro, Brasil. 